\title{
Comparative study between post-aural and per-meatal approach type-1 tympanoplasty.
}

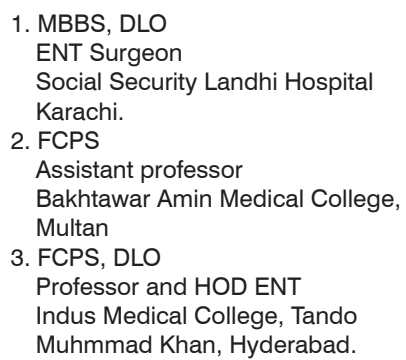

Correspondence Address:

Tahir Hussain Khan

ENT Surgeon

Sindh Employee's Social Security

Landhi Hospital Karachi.

tahirhussainkhan99@gmail.com

Article received on:

08/06/2020

Accepted for publication:

$18 / 12 / 2020$

\begin{abstract}
Tahir Hussain Khan ${ }^{1}$, Ashfaq Hussain Rana², Sohail A. Malik ${ }^{3}$
\end{abstract}
\begin{abstract}
Objective: To compare the results after tympanoplasty between post-aural and per-meatal approach. Study Design: Comparative study. Setting: Social Security Landhi Hospital, Karachi. Al-Tibri Medical College \& Hospital (Isra University Karachi Campus), old thana Malir, Karachi. Period: July 2017 till June 2018. Material \& Methods: In this study, 76 Patients of both genders with dry tympanic membrane perforations were included. They were aged between 18 to 40 years. Period of research was one year, study was started since July 2017 till June 2018. Patients were distributed into two groups, group-1 and group-2. 38 patients were included in every group. In group-1, post-aural approach tympanoplasty was done. In group-2, per-meatal approach tympanoplasty was performed. Observed results of both procedures after $1^{\text {st }}$ post-operated day, after $1^{\text {st }}$ post-operated week, after $1^{\text {st }}$ month and after $2^{\text {nd }}$ month post operatively. Variables were intensity of pain, bleeding, PTA (AC, BC and ABgap measured by tympanometer) and duration (time period) of surgical procedure. Result: In group-1 (post-aural approach tympanoplasty), out of 38 patients, 36 patients had intact grafted tympanic membrane while in group-2 (per-meatal approach tympanoplasty), 37 patients had intact grafted tympanic membrane and 1 patient had residual perforation. Smaller amount of bleeding was noted during surgery and post-operative in group-2, in comparison with group-1. All the dressing gauze were dry in per-meatal approach tympanoplasty group (group-2). Mean time period of surgery was less in per-meatal tympanoplasty (group-2) $65.1 \pm 3.7$ mins and mean time period of post-aural tympanoplasty (group-1) was $82.0 \pm 5.6$ mins. $P$ value was found to be significant i.e. $<0.001$. Consumed time period of surgery was also decreased in per-meatal tympanoplasty (group-2). After tympanoplasty, hearing status was also enhanced on PTA in both groups. Post- operatively, it was observed that AB gap was reduced in both groups. On $1^{\text {st }}$ post -operative day, Weber test was done, vibrating sound was heard (lateralized) in post-operated ears which ensured the safety of inner ear apparatus. Conclusion: Results of post-aural and per-meatal tympanoplasty were approximately same but per-meatal approach tympanoplasty is superior as it took shorter amount of time period, minimum post-operative pain and minimum post-operative bleeding.
\end{abstract}

Key words: $\quad$ Air Bone Gap, Air Conduction, Bone Conduction, Post-Aural Approach, PerMeatal Approach, Type-1 Tympanoplasty.

Article Citation: Khan TH, Rana AH, Malik SA. Comparative study between post-aural and per-meatal approach type-1 tympanoplasty. Professional Med J 2021; 28(1):125-130. https://doi.org/10.29309/TPMJ/2021.28.01.5154

\section{INTRODUCTION}

Chronic suppurative otitis media is persistent ear discharge (otorrhea) with perforation of tympanic membrane, discharge may be continuous or intermittent associated with conductive type of hearing loss. Initially, CSOM treated with medicine. When medical management failed, consider repair of perforated tympanic membrane for improvement of hearing. ${ }^{1}$

Pathophysiology of CSOM started with irritation of tympanic and later inflammation of middle ear mucous membrane. Dysfunction of eustachian tube play major role in pathology of CSOM. Obstruction of eustachian tube may lead to otitis media. Diseases of nose and paranasal sinuses influenced the middle ear environment. ${ }^{2}$

Tympanoplasty is very common operation for repair of perforated tympanic membrane. Since past several years, numerous efforts have been done by otologists for good surgical outcome. ${ }^{3}$ 
Incidence of CSOM is increasing day by day in developing countries due to poor hygiene, malnutrition and lack of awareness of health education. According to WHO, disease burden is more than 2 million. When proper treatment is not provided at right time, it may lead to irreversible changes with destruction of middle ear structures and causing complications such as labyrinthitis, facial nerve palsy, mastoiditis, lateral sinus thrombosis, meningitis and intra cranial abscess. ${ }^{4}$

For repair of tympanic membrane, underlay and overlay techniques used with temporalis facia or perichondrium. Tragal cartilage is also used as a graft material. ${ }^{5}$ Now a day's endoscope is used instead of microscope for per-meatal type 1 tympanoplasty. ${ }^{6}$

Adequate arearequired betweengraft and remnant of contact tympanic membrane for successful repair of perforation of tympanic membrane. ${ }^{7}$ Same day, bilateral tympanoplasty is quick, safe and more easy method. Conventionally, otologists avoid doing bilateral tympanoplasty due to complications. ${ }^{8}$

In developing countries, CSOM is the most common reason for hearing impairment. Burden of CSOM involved 65-330 million patients with ear discharge. ${ }^{9}$ Various graft materials have been used for tympanoplasty such as temporalis fascia, tragal cartilage, perichondrium, dura mater, vein, fat and skin. After tympanoplasty, intact graft is the surety of anatomical and functional achievement depends on decreased air-bone gap. ${ }^{10}$

\section{MATERIAL \& METHODS}

Seventy six (76) patients were included in the research. Two different hospitals. 1- Social Security Landhi Hospital Karachi. 2-Al-Tibri Medical College \& Hospital (Isra University, Karachi Campus), old Thana, Malir, Karachi after approval by ethical board (BASR-31/2017/1160). Study design was comparative and sampling technique was non probable, purposive. The research was one year since July 2017 till June 2018. All patients were distributed in group-1 and group-2 with 38 patients in each group.
Post-aural approach Type 1 tympanoplasty were performed in Social Security Landhi Hospital and per-meatal Type 1 tympanoplasty in Al-Tibri Medical College \& Hospital, Karachi. In group-1 (post-aural approach tympanoplasty), temporalis muscle fascia was utilized as a graft material and tragal cartilage was utilized as graft material in group-2 (per-meatal approach tympanoplasty). Before surgery, PTA test were recommended for hearing assessment to each patient in which air conduction (AC), bone conduction (BC) and airbone gap (AB-gap) were noted by tympanometer. On $1^{\text {st }}$ post-operated day, weber test was performed with tuning fork and it was lateralized towards post-operated ear which ensured the safety of inner ear.

Pain and bleeding noted on $1^{\text {st }}$ post-operated day, after $1^{\text {st }}$ week, after $1^{\text {st }}$ and $2^{\text {nd }}$ month. Integrity of grafted tympanic membrane and reduction of airbone gap was observed after 2 months by otoendoscopic examination and PTA.

\section{RESULT}

Various variables like Pain, Bleeding, PTA, weber test, examination of grafted tympanic membrane and time period of surgery in both approaches of tympanoplasty were observed. Table-I Showing comparison of pain after tympanoplasty between post-aural approach tympanoplasty (group-1) and per-meatal approach tympanoplasty (group-2). It denotes mild, moderate, severe and no pain on 1st post-operative day, after $1^{\text {st }}$ week of tympanoplasty, after $1^{\text {st }}$ month and after $2^{\text {nd }}$ month post-operatively. On $1^{\text {st }}$ post- operative day, 18 patients had no pain (pain free), mild pain in 19 patients and only 1 patient complaint moderate pain in per-meatal tympanoplasty (group-2) while in post-aural approach tympanoplasty (group-1), 8 patients pain free, mild pain in 26 patients and moderate pain in 4 patients. After $1^{\text {st }}$ week, in per-meatal tympanoplasty (group-2), 34 patients were pain free, 4 patients had mild pain while moderate and severe pain were not noted. In post-aural approach tympanoplasty (group-1), 12 patients free of pain, 22 patients had mild pain, 2 patients had moderate pain and 2 patients had severe pain. Only 1 patient complaint mild pain after one month in both groups. After 2 months 
all patients were pain free in group- 2 while only 1 patients complaint mild pain in group-1.

Figure-1 demonstrates the graphical depiction of bleeding pattern after tympanoplasty in both groups. Blood soaked dressing found in 5 patients in per-meatal tympanoplasty while in post-aural tympanoplasty it was in 37 patients. Bleeding was smaller in amount in group-2(per-meatal approach tympanoplasty) in comparison with group-1 (post-aural) because of small incision.

Figure-2 demonstrates integrity of grafted tympanic membrane in group-1 (post-aural tympanoplasty) and in group-2(per-meatal tympanoplasty).37patients out of 38 had intact grafted tympanic membrane in per-meatal tympanoplasty (group-2) while 36 out of 38 had intact grafted tympanic membrane in post-aural tympanoplasty in group-1. In group-1, success percentage was $94.73 \%$ while in group-2, graft success percentage was $97.73 \%$.

Figure-3 demonstrates graphical depiction of (AB-gap) air bone gap reduction in both groups. AB-gap reduction seen in 37 patients in per-meatal tympanoplasty while in post-aural tympanoplasty it was not reduced in 2 patients due to lateralization of graft.

Table-Il Showing PTA results, mean air conduction, bone conduction, AB-gap, standard deviation and $p$-value in both group's pre and post-tympanoplasty procedures. Air conduction was reduced from $42.68 \mathrm{~dB}$ to $27.18 \mathrm{~dB}$ in permeatal approach tympanoplasty and in postaural approach tympanoplasty it was reduced from $42.0 \mathrm{~dB}$ to $26.74 \mathrm{~dB}$. No change seen in bone conduction post-operatively in both groups which ensured the safety of vestibule-o-cochlear system. AB-gap reduced from 29.42dB to 15.47dB in per-meatal approach tympanoplasty (group-2) while in group-1, it was reduced from $29.37 \mathrm{~dB}$ to $15.42 \mathrm{~dB}$. P-value was found significant i.e. less than 0.001 in both groups after tympanoplasty.

Table-III Shows comparison of duration of tympanoplasty in post-aural (group-1) and permeatal approach tympanoplasty (group-2). In group-1, time period of surgery was $82.0+5.6$ min while in group-2, it was $65.1+3.7 \mathrm{~min}$. Less amount of time taken in per-meatal approach tympanoplasty in comparison with post-aural approach tympanoplasty. P-value was found significant i.e. $<0.001$. Weber test was performed on very next day with tuning fork and vibrating sound was heard (lateralized) in post-operated ears in all patient in both of groups which ensured that there were no damage of middle ear's ossicles and vestibulo-cochlear apparatus after tympanoplasty.

\begin{tabular}{|c|c|c|c|c|c|}
\hline Tympanoplasty & Pain (VAS) & $\begin{array}{l}1^{\text {st }} \text { post- } \\
\text { operated day }\end{array}$ & $\begin{array}{l}\text { After } 1^{\text {st }} \text { post- } \\
\text { op. week }\end{array}$ & $\begin{array}{l}\text { After 1st Month(post- } \\
\text { operated) }\end{array}$ & $\begin{array}{l}\text { After 2nd months } \\
\text { (post-operated) }\end{array}$ \\
\hline \multirow{3}{*}{$\begin{array}{l}\text { Post- aural } \\
\text { Group-1 }\end{array}$} & No & 8 & 12 & 37 & 37 \\
\hline & Mild & 26 & 22 & 1 & 1 \\
\hline & Severe & 0 & 2 & 0 & 0 \\
\hline \multirow{2}{*}{$\begin{array}{l}\text { Per-meatal } \\
\text { Group-2 }\end{array}$} & No & 18 & 34 & 37 & 38 \\
\hline & Mild & 19 & 4 & 1 & 0 \\
\hline
\end{tabular}

Table-I. Comparison of pain after tympanoplasty between post-aural and per-meatal approach. 


\begin{tabular}{|c|c|c|c|c|c|}
\hline \multicolumn{3}{|c|}{ Surgical Procedure of Tympanoplasty } & Mean Value in (dB) & S.D. value & $P$ value \\
\hline \multirow{6}{*}{$\begin{array}{l}\text { (Group-1) } \\
\text { Post-aural approach }\end{array}$} & \multirow{2}{*}{ Air Conduction } & Pre-op. & 42.0 & 2.526 & \multirow{2}{*}{$<0.001$} \\
\hline & & Post-op. & 26.74 & 2.596 & \\
\hline & \multirow{2}{*}{ Bone Conduction. } & Pre-op. & 12.87 & 2.195 & \multirow{2}{*}{0.793} \\
\hline & & Post-op. & 13.00 & 2.169 & \\
\hline & \multirow{2}{*}{ AB-gap } & Pre-op. & 29.37 & 3.191 & \multirow{2}{*}{$<0.001$} \\
\hline & & Post-op. & 15.42 & 1.388 & \\
\hline \multirow{6}{*}{$\begin{array}{l}\text { (Group-2) } \\
\text { Per-meatal approach }\end{array}$} & \multirow{2}{*}{ Air Conduction } & Pre-op. & 42.68 & 2.055 & \multirow{2}{*}{$<0.001$} \\
\hline & & Post-op. & 27.18 & 1.872 & \\
\hline & \multirow{2}{*}{ Bone Conduction. } & Pre-op. & 13.24 & 2.247 & \multirow{2}{*}{0.715} \\
\hline & & Post-op. & 13.05 & 2.130 & \\
\hline & \multirow{2}{*}{ AB-gap. } & Pre-op. & 29.42 & 3.099 & \multirow{2}{*}{$<0.001$} \\
\hline & & Post-op. & 15.47 & 1.688 & \\
\hline
\end{tabular}

Table-II. Comparison of PTA results between post-aural and per-meatal approach tympanoplasty.

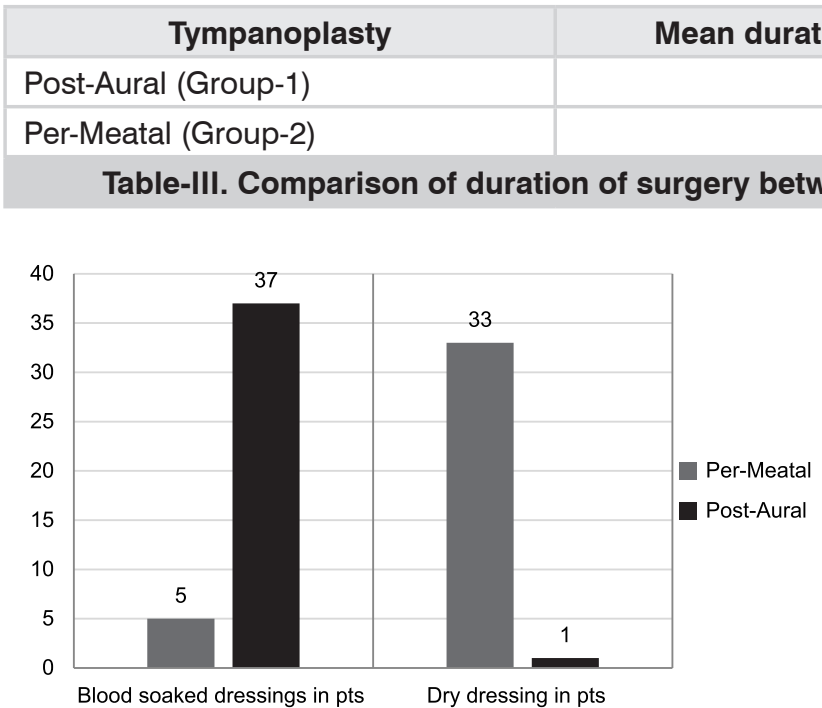

Flgure-1. Post-operated bleeding comparison between post-aural and per-meatal tympanoplasty.

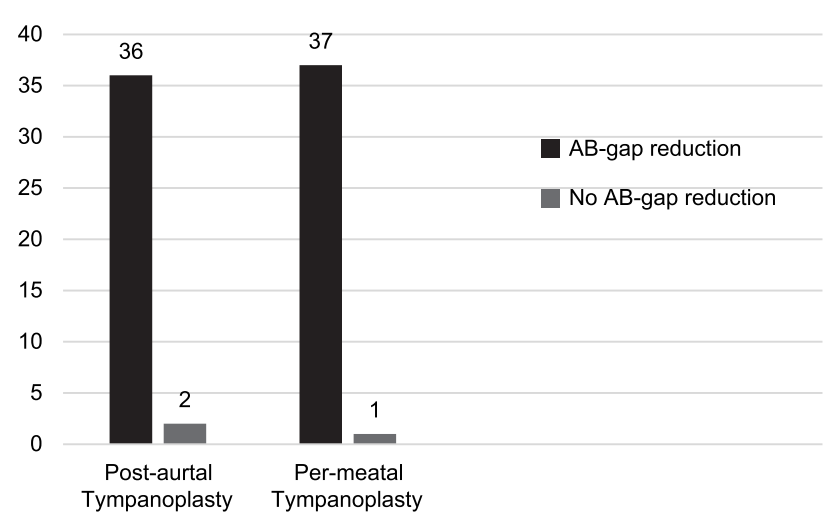

Figure-3. Showing reduction of AB-gap between post-aural and per-meatal approach tympanoplasty.

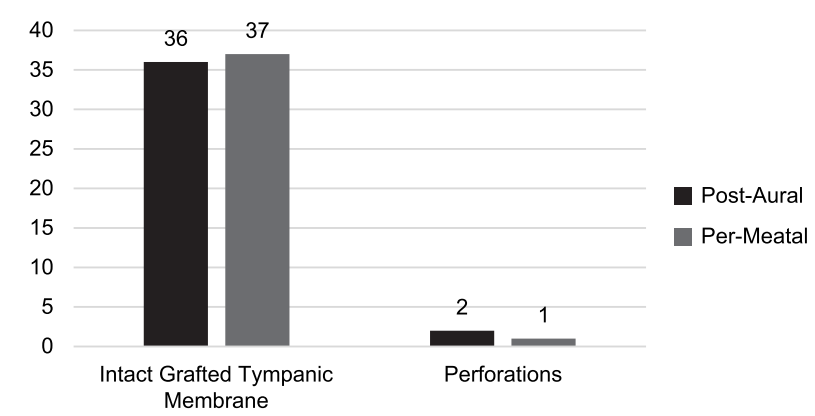

Figure-2. Showing Integrity of grafted tympanic membrane after 2 months in post-aural and per-meatal tympanoplasty.

\section{DISCUSSION}

In a study pain was measured on $1^{\text {st }}$ post-operated day, pain score in per-meatal (endoscopic) tympanoplasty was 3.5 while pain score in postaural (microscopic) tympanoplasty was 5.4. This study revealed that pain score was more in post-aural tympanoplasty as compared with permeatal tympanoplasty. ${ }^{11}$

Pain was felt in 1 patient out of 52 in per-meatal (endoscopic) tympanoplasty while it was in 10 patients out of 48 patients in post aural (microscopic tympanoplasty). This study co- 
relating with our study. ${ }^{12}$

According to a study the average time required for surgery in endoscopic permeatal approach tympanoplasty group was 78.13 minutes while in microscopic post-aural approach tympanoplasty group was 94.38 minutes. This is correlating with our study. ${ }^{13}$

In the same study graft uptake rate in per-meatal approach tympanoplasty group was $92.9 \%$ whereas in post-aural tympanoplasty group, it was $85.5 \% .^{13}$

In accordance with the study findings that success of graft uptake rate was $95 \%$ in postaural approach tympanoplasty group and in permeatal approach tympanoplasty group was $91 \%$. Air Bone gap (AB-gap) decline was $23.68 \mathrm{~dB}$ in post-aural approach tympanoplasty group and in per-meatal approach tympanoplasty group, it was $16.13 \mathrm{~dB} .^{14}$

Aftab et al., (2016) reported in his study that time period consumed in trans-canal approach tympanoplasty was 62.37 minutes and in post-aural approach tympanoplasty, it was 72.15 minutes. P-value was $<0.001$ which is significant. Time duration of per-meatal approach tympanoplasty was a lesser amount as compared to post-aura approach tympanoplasty. This study is also correlating with our study. ${ }^{11}$

A study showed that average time period of surgery was 75.5 minutes in post-aural approach tympanoplasty while average time period was 50.4 minutes in per-meatal approach tympanoplasty. This study showed that time period was lesser in per-meatal approach tympanoplasty group as compared with post-aural approach tympanoplasty. ${ }^{15}$ This is also similar with our study.

In a study air-bone gap (AB-gap) decline was found $20.47 \mathrm{~dB}$ in post-aural approach tympanoplasty while in per-meatal approach tympanoplasty, airbone gap (AB-gap) reduction was $17.4 \mathrm{~dB} .{ }^{16}$

In a study it is reported that mean pre-operative air conduction was $35 \mathrm{~dB}$ and post-operative mean air conduction changed into $20 \mathrm{~dB}$, hearing gain was $15 \mathrm{~dB} .{ }^{17}$

This study is also co-relating with our study.

It has also been reported that average hearing level before tympanoplasty was $59 \mathrm{~dB}$ and after per-meatal tympanoplasty average hearing level of $27 \mathrm{~dB}$ with average $\mathrm{AB}$-gap gain $11 \mathrm{~dB} .^{18}$

In a study it is reported that the success of graft uptake rate in per-meatal approach tympanoplasty group was $92 \%$ and in post-aural approach tympanoplasty, it was $95 \%$. AB-gap gain $18.9 \mathrm{~dB}$ to $9.2 \mathrm{~dB}$ with $p$ value $<0.001$ showed significant. ${ }^{18}$

\section{CONCLUSION}

Per-meatal approach type-1 tympanoplasty is considered to be better than post-aural approach type-1 tympanoplasty as it consumed less amount of time, lesser amount of bleeding during and after surgery because of small area of incision and less pain. Although graft uptake rate and hearing enhancement (improvement) were also same in both groups.

Copyrights $(18$ Dec, 2020

\section{REFERENCES}

1. Al Anazy FH, Alobaid FA, Alshiha WS. Sensorineural hearing loss following tympanoplasty surgery: A prospective cohort study. The Egyptian Journal of Otolaryngology. 2016 Apr 1; 32(2):93.

2. Dhanasekaran SV, Nair JS, Raja K, Gopalakrishnapillai GK, Chandran AK, Radhakrishnan S. A clinical study on the influence of sinusitis in chronic suppurative otitis media. Bengal Journal of Otolaryngology and Head Neck Surgery. 2016 Aug 26; 24(2):49-53.

3. Patel J, Aiyer RG, Gajjar Y, Raval J, Suthar PP. Endoscopic tympanoplasty vs microscopic tympanoplasty in tubotympanic csom: A comparative study of 44 cases. International Journal of Research in Medical Sciences. 2017 Jan 10; 3(8):1953-7.

4. Khatoon A, Rizvi M, Sultan A, Khan F, Sharma M, Shukla I, Khan HM. Chronic suppurative otitis media: A clinico-microbiological menace. Int J Res Med Sci. 2015 Aug; 3:1932-6.

5. Karatas M, Dogan S. Inlay butterfly cartilage tympanoplasty for large central perforations. The European Research Journal. 2017; 3(3):259-63. 
6. Singh MN, Hamam PD, Lyngdoh NC, Priyokumar OS. Evaluation of hearing status in pre and postoperative endoscopic type 1 tympanoplasty and its influencing factors. Journal of Medical Society. 2014 Sep $1 ; 28(3): 166$.

7. Bhushan K, Himani D, Joginder G, Vikas K, Yadav SPSet al. Staining in Tympanoplasty; Is Methylene blue Rationale?. Glob j Oto 1(2): GJO.MS.ID.555557 (2015)

8. Daneshi A, Jahandideh H, Daneshvar A, Safdarian M. Bilateral same-day endoscopic transcanal cartilage tympanoplasty: Initial results. Brazilian journal of otorhinolaryngology. $2017 \mathrm{Jul}$; 83(4):411-5.

9. Hasan N, Ahmed S, Zaman S, Ferdousi S, Khaleque MA, Bari L. CSOM Causing Tympanic Membrane Perforation and Impaired Hearing: Improved by Homeopathy. Journal of Advances in Medicine and Medical Research. 2017 May 4:1-9.

10. Yegin $Y$, Çelik M, Koç AK, Küfeciler L, Elbistanlı MS, Kayhan FT. Comparison of temporalis fascia muscle and full-thickness cartilage grafts in type 1 pediatric tympanoplasties. Brazilian journal of otorhinolaryngology. 2016 Dec; 82(6):695-701.

11. Ahmed A, Alam S, Hashmi SF, Hasan SA. A Prospective Study Comparing the Results of Endoscope Assisted Versus Microscope Assisted Myringoplasty.

12. Singh NK, NagpurePS, Yadav M, Chavan S. Comparative study of permeatal sandwich tympanoplasty and postaural underlay technique. Journal of clinical and diagnostic research: JCDR. 2016 Apr; 10(4):MC01.
13. Sanji RR, Channegowda C, Patil SB. Retrospective evaluation of the surgical result of tympanoplasty for inactive chronic otitis media and comparison of endoscopic versus microscopic tympanoplasty. Indian Journal of Otology. 2016 Jul 1; 22(3):171

14. Sinha M. Colonial masculinity: The 'manly Englishman'and the 'effeminate Bengali'in the late nineteenth century. Manchester University Press; 2017 Mar 1.

15. Huang TY, Ho KY, Wang LF, Chien CY, Wang HM. A comparative study of endoscopic and microscopic approach type 1 tympanoplasty for simple chronic otitis media. The journal of international advanced otology. 2016 Apr 1; 12(1):28.

16. Shoeb M, Gite V, Bhargava S, Mhashal S. Comparison of surgical outcomes of tympanoplasty assisted by conventional microscopic method and endoscopic method. Int J Otorhinolaryngology Head Neck Surg. 2016 Oct; 2:184-8.

17. Dündar R, Kulduk E, Soy FK, Aslan M, Hanci D, Muluk NB, Cingi C. Endoscopic versus microscopic approach to type 1 tympanoplasty in children. International journal of pediatric otorhinolaryngology. 2014 Jul 1; 78(7):1084-9.

18. Kumar N, Chilke D, Puttewar MP. Clinical profile of tubotympanic CSOM and its management with special reference to site and size of tympanic membrane perforation, eustachian tube function and three flap tympanoplasty. Indian Journal of Otolaryngology and Head \& Neck Surgery. 2012 Mar 1; 64(1):5-12.

\begin{tabular}{|c|c|c|c|}
\hline \multicolumn{3}{|c}{ AUTHORSHIP AND CONTRIBUTION DECLARATION } \\
\hline Sr. \# & Author(s) Full Name & \multicolumn{1}{|c|}{ Contribution to the paper } & Author(s) Signature \\
\hline 1 & Tahir Hussain Khan & $\begin{array}{l}\text { Performed surgical procedures } \\
\text { under supervision of Professor } \\
\text { Sohail A Malik. Thesis writing and } \\
\text { did research. } \\
\text { Formatting and editing article and } \\
\text { helped in data analysis. } \\
\text { Supervised the research. }\end{array}$ \\
\hline 3 & Sohail A. Malik & Ashfaq Hussain Rana \\
\hline
\end{tabular}

